15

\title{
Магнитоупругие свойства пленок железо-иттриевого граната, полученных ионно-лучевым распылением на подложках Si и GaAs
}

\author{
(C) С.Л. Высоцкий, ${ }^{1,2}$ Ю.В. Никулин, ${ }^{1,2}$ А.В. Кожевников, ${ }^{1}$ Ю.В. Хивинцев, ${ }^{1,2}$ В.К. Сахаров, ${ }^{1}$ А.С. Джумалиев, ${ }^{1,2}$ \\ Ю.А. Филимонов, ${ }^{1,2}$ А.И. Стогний, ${ }^{3}$ С.А. Никитов ${ }^{4}$
}

${ }^{1}$ Саратовский филиал ИРЭ им. В.А. Котельникова РАН, 410019 Саратов, Россия

${ }^{2}$ Саратовский государственный университет им. Н.Г. Чернышевского, 410012 Саратов, Россия

${ }^{3}$ ГНПО „НПЦ НАН Беларуси по материаловедению“, 220072 Минск, Беларусь

${ }^{4}$ Институт радиотехники и электроники им. В.А. Котельникова РАН, 125009 Москва, Россия

e-mail: vysots।@gmail.com

Поступило в Редакцию 15 ноября 2019 г.

В окончательной редакции 15 ноября 2019 г.

Принято к публикации 23 января 2020 г.

Исследовано влияние деформаций растяжения на спектр ферромагнитного резонанса субмикронных поликристаллических пленок железо-иттриевого граната, полученных ионно-лучевым распылением на подложках кремния и арсенида галлия. По величине частотного сдвига максимума поглощения в спектре ферромагнитного резонанса были рассчитаны магнитоупругие постоянные пленок на обеих подложках, величина которых не превышала 16\% от значений объемного поликристаллического граната. Предложен подход к увеличению эффективности электрической перестройки частоты в композитных мультиферроидных структурах за счет комбинации статических и динамических (вызванных пьезоэффектом) деформаций растяжения.

Ключевые слова: ферромагнитный резонанс, железо-иттриевый гранат, магнитоупругая постоянная, кремний, арсенид галлия.

DOI: 10.21883/JTF.2020.07.49460.363-19

\section{Введение}

Наличие в пленках железо-иттриевого граната (ЖИГ) магнитоупругих свойств делает их перспективными при создании композитных мультиферроидных структур для устройств стрейнтроники [1]. На основе пленок ЖИГ могут быть разработаны энергоэффективные устройства управления фазой, временем задержки, полосой фильтрации, а также бистабильностью спиновых волн [2,3]. В то же время используемая технология жидкофазной эпитаксии (ЖФЭ) [4] получения пленок ЖИГ существенно ограничивает перспективы их интеграции с полупроводниковыми технологиями, результатом которой может быть создание монолитных гибридных устройств. В этой связи в последнее время существенно возрос интерес к альтернативным технологиям получения пленок ЖИГ и, в частности, к методу ионно-лучевого распыления [5] не только на подложки ГГГ (гадолинийгаллиевый гранат) [6], но и на полупроводниковые подложки [7-9]. В настоящей работе сообщается о результатах исследования магнитоупругих свойств пленок ЖИГ, полученных методом ионно-лучевого испарения на подложки $\mathrm{Si}$ и GaAs. По аналогии с работами [10-13] мы использовали эффект сдвига частоты ферромагнитного резонанса (ФМР) $\Delta \Omega$ под влиянием деформаций рас- тяжения для определения магнитоупругих постоянных пленок ЖИГ/Si и ЖИГ/GaAs. Также рассматривается способ повышения эффективности электрической перестройки частоты ФМР в композитных мультиферроидных структурах на основе пленок ЖИГ/Si и ЖИГ/GaAs. Для случая, когда деформации растяжения $\varepsilon$ вызваны изгибом пленки ЖИГ, показано, что величина частотного сдвига $\Delta \Omega$ спектра ФМР, вызванного подачей напряжения на пьезоэлектрик, может быть увеличена в разы за счет комбинации статических и динамических (вызванных пьезоэффектом) деформаций.

\section{Исследуемые структуры}

Эксперименты выполнялись с пленками ЖИГ/Si и ЖИГ/GaAs, полученными с использованием технологии ионно-лучевого распыления [4]. На рис. 1 и 2 для пленок ЖИГ/Si и ЖИГ/GaAs приведены полученные с помощью электронного микроскопа изображения скола пленок (рис. 1, $a$ и 2, $a$ соответственно), полученные с помощью атомно-силового микроскопа (АСМ) изображения участков поверхности пленок (рис. $1, b$ и $2, b)$ и дифрактограммы (рис. $1, c$ и 2,c), полученные методом рентгеновской дифракции на дифрактометре ДРОН-4 с фокусировкой по плоскому образцу в геомет- 

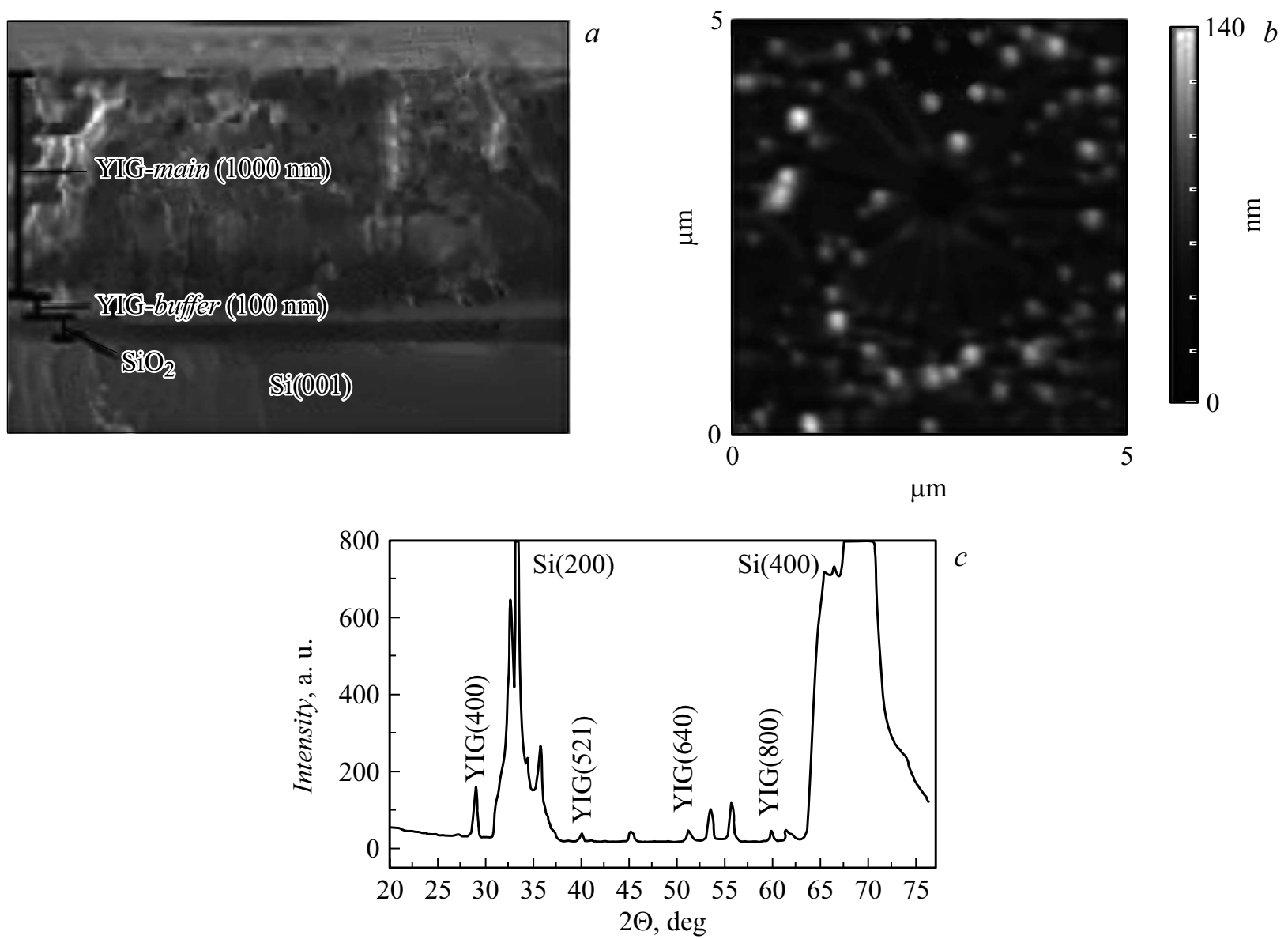

Рис. 1. Пленка ЖИГ/Si: $a-$ изображение скола, полученное с помощью электронного микроскопа, $b-$ изображение участка поверхности пленки, полученное с помощью АСМ, $c$ - дифрактограмма.

рии Брэгга-Брентано (схема $\theta-2 \theta, \mathrm{Cu}-K_{\alpha}$-излучение, $\lambda \approx 0.15418 \mathrm{~nm})$. При напылении на подложку $\mathrm{Si}$, толщина которой составляла $D_{\mathrm{Si}} \approx 440 \mu \mathrm{m}$, предварительно напылялся буферный слой ЖИГ толщиной $0.15 \mu \mathrm{m}$. Для пленки ЖИГ, осажденной на подложку GaAs толщиной $D_{\mathrm{GaAs}} \approx 490 \mu \mathrm{m}$, в качестве буферного слоя использовался аморфный слой $\mathrm{AlO}_{x}$ толщиной до $10 \mathrm{~nm}$. Толщина пленки ЖИГ/Si составляла $1000 \mathrm{~nm}$, пленки ЖИГ/GaAs - $400 \mathrm{~nm}$ (рис. $1, a, 2, a)$. Из рис. $1, b$ и $2, b$ видно, что исследуемые пленки имеют зернистую структуру с размером зерна от долей до единиц микрон. Из сравнения рис. $1, a, 2, a$ можно видеть, что для структуры ЖИГ/GaAs неоднородность интерфейса пленка-подложка гораздо выше, чем для ЖИГ/Si. Это проявляется в большей шероховатости интерфейса и неоднородности адгезии пленки ЖИГ к подложке GaAs, что приводит к частичному отслаиванию пленки от подложки. Дифракционные линии на рис. 1, $c$ и 2, c совпадают в пределах погрешности измерений и свидетельствуют о поликристаллической структуре пленок ЖИГ.

Намагниченность пленок $4 \pi M$ определялась с помощью метода ФМР на частоте $9.95 \mathrm{GHz}$ аналогично тому, как описано в [14]. Для пленок ЖИГ/Si намагниченность рабочего слоя составила $4 \pi M \approx 1.49 \mathrm{kG}$, для буферного слоя $4 \pi M \approx 1.28 \mathrm{kG}$. При этом ширина линии ФМР составила $\Delta H \approx 120$ Oе. Пленка ЖИГ/GaAs имела намагниченность $4 \pi M \approx 1.53 \mathrm{kG}$ и ширину линии ФМР $\Delta H \approx 160$ Oe.

\section{Влияние деформаций на спектр ФМР пленок ЖИГ/Si и ЖИГ/GaAs}

Исследование магнитоупругих свойств проводилось с помощью метода широкополосного ФМР аналогично [14]. Образцы вырезались в виде прямоугольников 1 (рис. 3,a) размерами $4 \times 10 \mathrm{~mm}$ и помещались на опорах 2 высотой $130 \mu \mathrm{m}$, размещенных соосно с центральным проводником микрополосковой линии 3 симметрично по обе стороны от него на расстоянии $S=5 \mathrm{~mm}$ друг от друга (рис. $3, a, b)$. Постоянное магнитное поле $H=0.2-1 \mathrm{kOе}$ прикладывалось касательно к поверхности образцов вдоль микрополосковой линии. При этом в частотной зависимости потерь $S_{21}(f)$ в микрополосковой линии наблюдалась область увеличения потерь (рис. 3,c), в которой частота максимальных потерь $f_{r}$ отождествлялась с частотой ФМР. Исследовалась зависимость частоты $f_{r}$ при деформации 

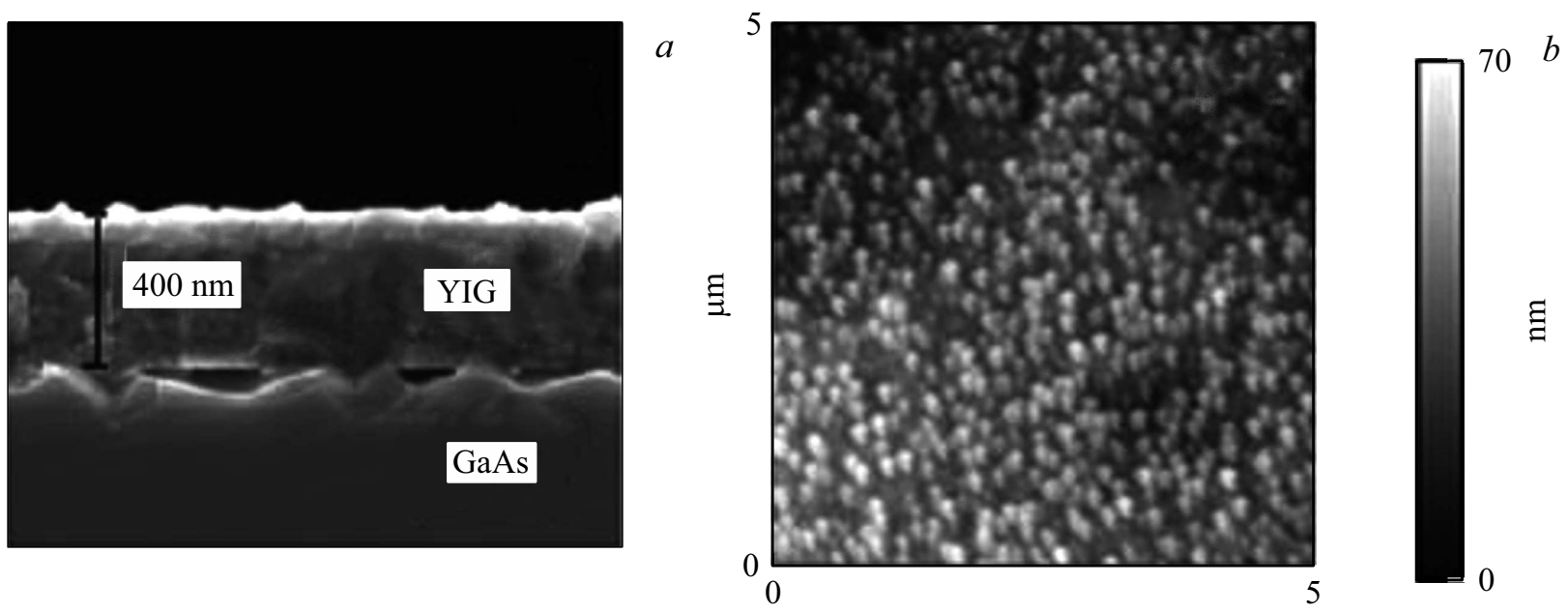

$\mu \mathrm{m}$

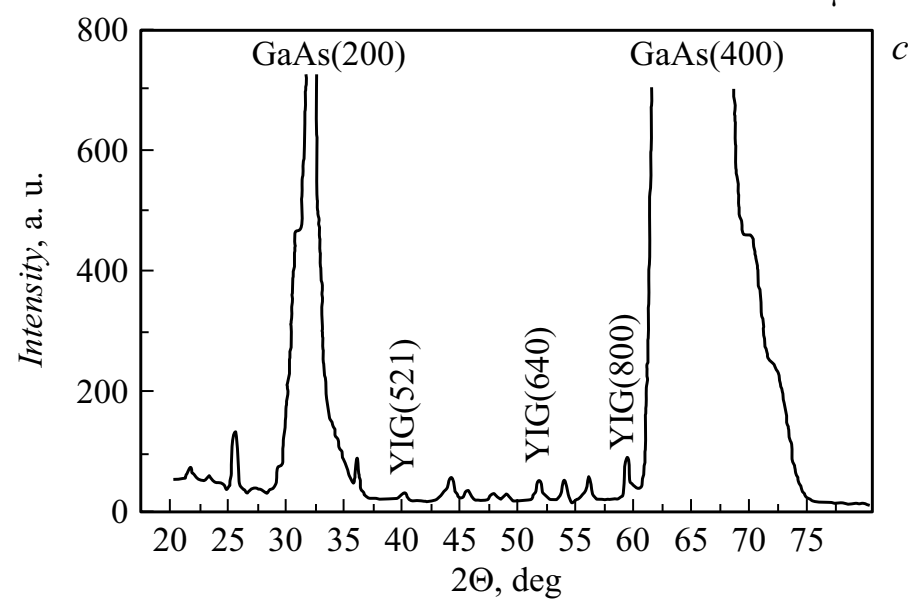

Рис. 2. Пленка ЖИГ/GaAs: $a-$ изображение скола пленки, полученное с помощью электронного микроскопа, $b-$ изображение участка поверхности пленки, полученное с помощью АСМ, $c$ - дифрактограмма.

растяжения пленки за счет давления, создаваемого грузом $P$, микрометрической подачей или актюатором [15]. Направление усилия показано стрелкой на рис. 3, $a, b$. На рис. $3, d$ приведены зависимости частоты $f_{r}$ от веса груза $P$ для исследуемых пленок и эталонного образца, в качестве которого бралась пленка ЖИГ, выращенная на подложке ГГГ толщиной $D_{\mathrm{GGG}} \approx 530 \mu \mathrm{m}$ методом ЖФЭ. Эталонная пленка имела толщину $0.58 \mathrm{~nm}$, намагниченность насыщения $4 \pi M \approx 1.75 \mathrm{kG}$.

Из рис. 3, $d$ видно, что для структуры ЖИГ/Si (кривая 1) зависимость $f_{r}(P)$ имеет монотонный характер аналогично [14] так же, как и для ЖФЭ пленки ЖИГ (кривая 3). Кривая 2, полученная для структуры ЖИГ/GaAs, демонстрирует скачкообразные, немонотонные изменения частоты ФМР при изменении степени деформации. Кроме того, зависимость $f_{r}(P)$ в пленках ЖИГ/GaAs характеризовалась гистерезисом. Возможной причиной такого характера зависимости $f_{r}(P)$ в пленках ЖИГ/GaAs является изменение характера интерфейса пленка-подложка при деформациях растяжения.

Результаты измерений были использованы для определения магнитоупругой постоянной полученной пленки
ЖИГ аналогично [14]. В пренебрежении анизотропией магнитоупругих свойств и в приближении однородности параметров пленки по толщине выражение для частоты $f_{r}$ может быть представлено в виде [10-13]:

$$
f_{r}=\gamma \sqrt{\left(H+H_{m e}\right)\left(H+4 \pi M_{0}\right)},
$$

где $\gamma=2.8 \mathrm{MHz} / \mathrm{Oe}-$ гиромагнитное отношение, $H_{m e}$ - поле магнитоупругой анизотропии в пленке, определяемое выражением:

$$
H_{m e}=\frac{2 B \cdot(1+v) \varepsilon}{M_{0}}
$$

где $B-$ магнитоупругая константа, $v-$ коэффициент Пуассона, $\varepsilon$ - относительное удлинение пленки под нагрузкой. Для случая, когда деформации создаются с помощью микрометрической подачи или пьезоэлектрическим актюатором, относительное удлинение пленки $\varepsilon$ можно рассчитать по длине хорды $S$ и стрелке „прогиба“ $h$ (рис. $3, b)$ с помощью соотношения [16]

$$
\varepsilon=\frac{\Delta S}{S} \approx \frac{8 h^{2}}{3 S^{2}} .
$$



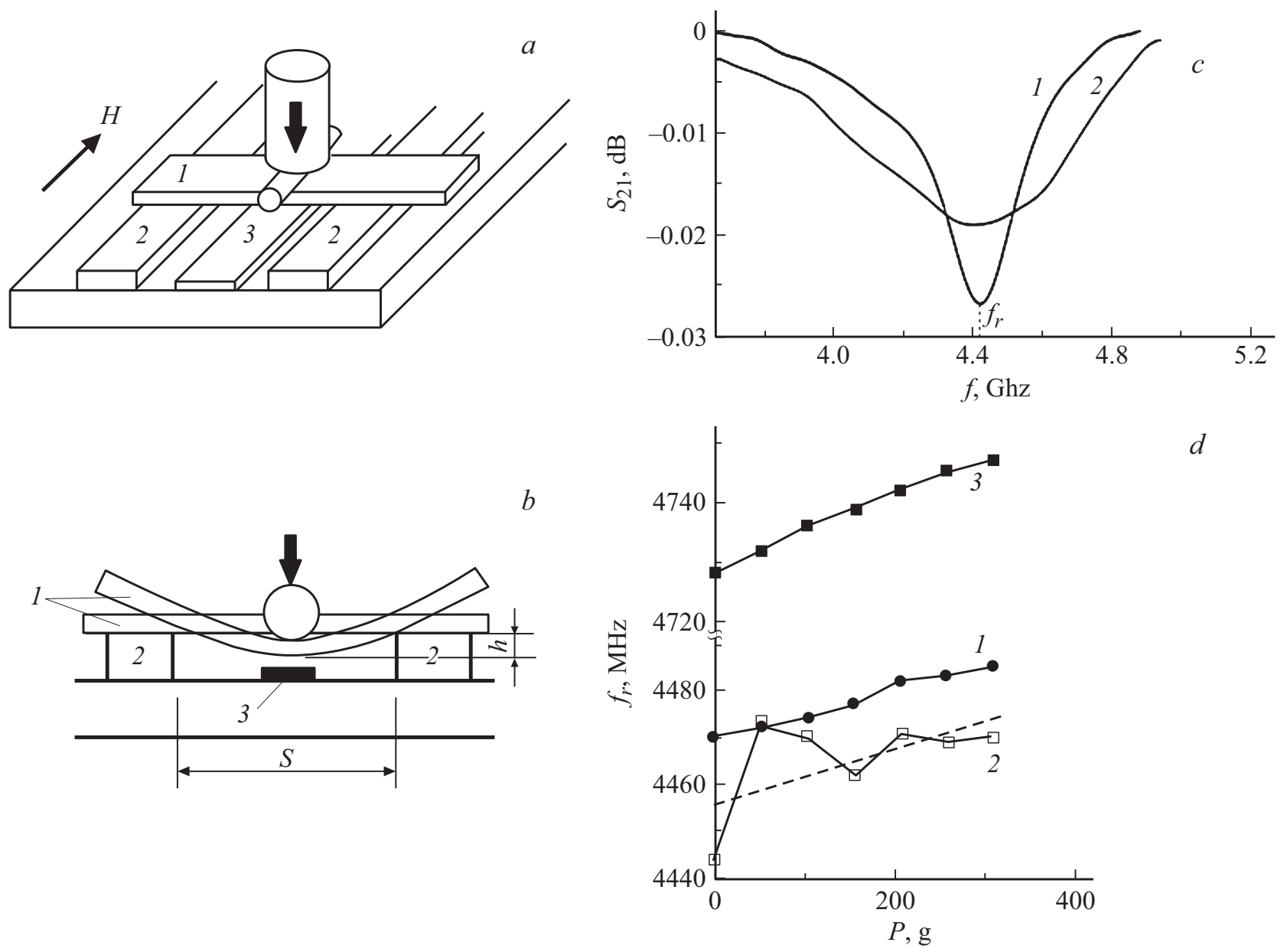

Рис. 3. $a, b-$ схематическое изображение конструкции макета, $c$ - зависимость $S_{21}(f)$ для структур жИГ/Si (кривая 1$)$ и ЖИГ/GaAs (кривая 2), $d$ - зависимость $f_{r}(P)$ для пленок ЖИГ/Si (кривая 1), ЖИГ/GaAs (кривая 2) и ЖФЭ пленки ЖИГ (кривая 3), $H=1 \mathrm{kOe}$.

В случае, когда деформация пленки вызвана грузиком весом $P$, для расчета относительного удлинения пленки $\varepsilon$ воспользуемся выражением [12]:

$$
\varepsilon=\frac{3 P S}{2 E \cdot b \cdot D^{2}},
$$

где $E$ - модуль Юнга.

В приближении $H_{m e} \ll H, 4 \pi M$ из (2) и (3) можно оценить величину сдвига частоты пика поглощения $\Delta \Omega(P) \approx f_{r}(P)-f_{0}$ с помощью соотношений

$$
\Delta \Omega(P) \approx \frac{f_{m e} f_{B}}{2 f_{0}},
$$

где $f_{m e}=\gamma H_{m e}, f_{B}=\left(f_{H}+f_{m}\right), f_{m}=\gamma 4 \pi M, f_{H}=\gamma H$, $f_{0}=f_{r}(P=0)$.

С помощью (4), (5) и результатов измерений значений $\Delta \Omega(P)$ (рис. 3) можно получить оценку магнитоупругих постоянных исследованных пленок

$$
B \approx \frac{M \Delta \Omega}{(1+v) \varepsilon \gamma} \cdot \frac{f_{0}}{f_{B}}
$$

С учетом сказанного для полученного при максимальной массе грузика $m \approx 320 \mathrm{~g}$ для пленок ЖИГ/Si значения сдвига $\Delta \Omega \approx 20 \mathrm{MHz}$ и параметрах, отвечающих подложке $\mathrm{Si}(100)\left(D_{\mathrm{Si}} \approx 440 \mu \mathrm{m} \approx 0.44 \mathrm{~mm}\right.$, модуль Юнга для $\mathrm{Si}(100) E_{\mathrm{Si}} \approx 1.3 \cdot 10^{12} \mathrm{dyn} / \mathrm{cm}^{2}$ и коэффициент Пуассона $\left.v_{\mathrm{Si}} \approx 0.266[17]\right)$ получим значение магнитоупругой постоянной для исследованной пленки ЖИГ $/ \mathrm{Si}$ $B \approx 0.8 \cdot 10^{6} \mathrm{erg} / \mathrm{cm}^{3}$, что составляет примерно $16 \%$ от величины этого параметра для объемного поликристаллического ЖИГ $\left(B \approx 4.95 \cdot 10^{6} \mathrm{erg} / \mathrm{cm}^{3}\right)$, полученного с использованием приведенных в $[18,19]$ параметров.

Для структур ЖИГ/GaAs немонотонный характер зависимости $f_{r}(P)$ затрудняет проведение подобных расчетов. Мы провели приблизительную оценку для параметров $\mathrm{GaAs}\left(D_{\mathrm{GaAs}} \approx 490 \mu \mathrm{m} \approx 0.49 \mathrm{~mm}\right.$, модуль Юнга $E_{\mathrm{GaAs}} \approx 0.83 \cdot 10^{12} \mathrm{dyn} / \mathrm{cm}^{2}$ и коэффициент Пуассона $\left.v_{\mathrm{GaAs}} \approx 0.31\right)$ в предположении, что величина $\Delta \Omega$ может быть определена из аппроксимированной экспериментальной зависимости $f_{r}(P)$ (штриховая кривая на рис. 3). Проведенный расчет дает значение $B \approx 0.6 \cdot 10^{6} \mathrm{erg} / \mathrm{cm}^{3}$. 

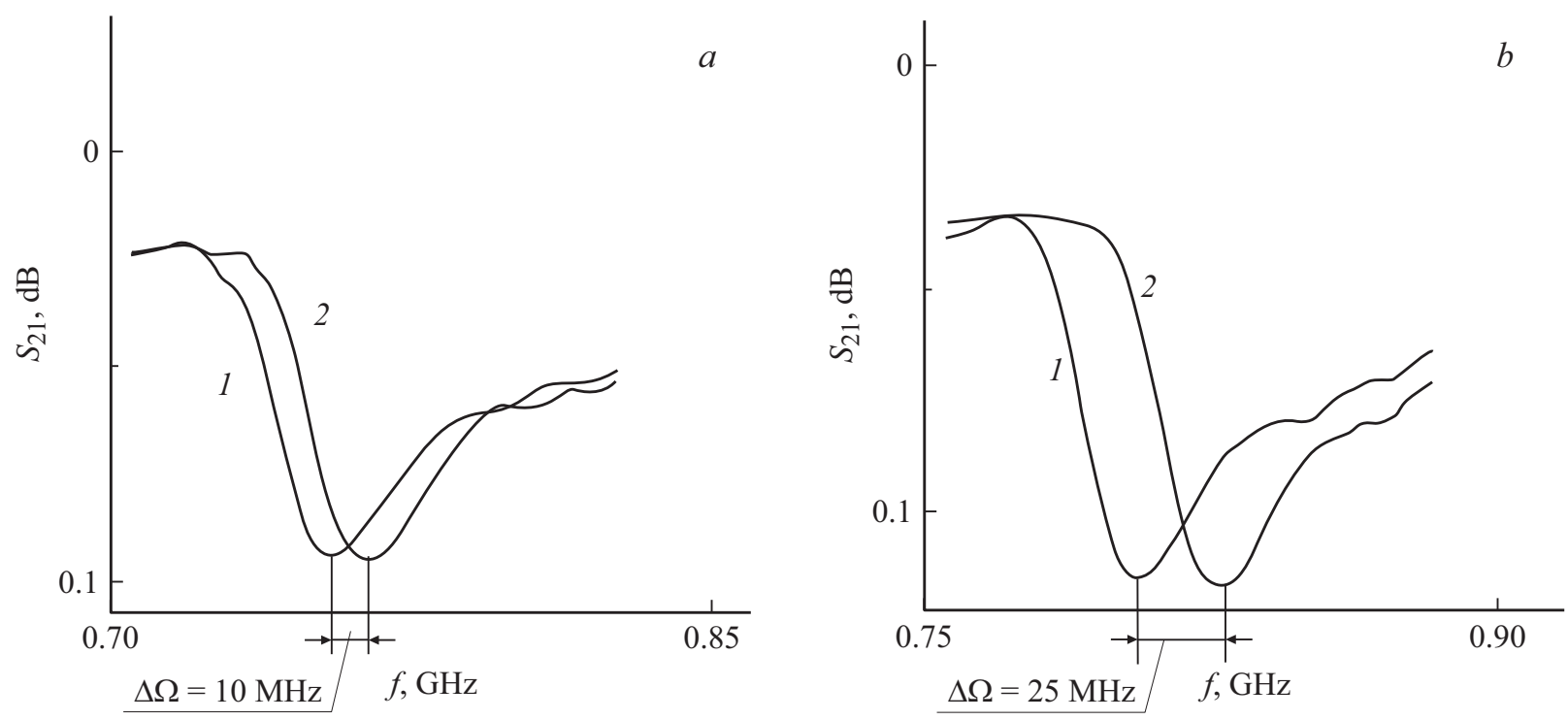

Рис. 4. Вид зависимостей $S_{21}(f)$ для структуры ЖИГ/Si при величине подаваемого на актюатор напряжения 0 (кривые 1 ) и $150 \mathrm{~V}$ (кривые 2$)$ в отсутствие дополнительного изгибающего усилия $(a)$ и при деформации, обеспечивающей стрелу прогиба $20 \mu \mathrm{m}(b)$, $H=26$ Oe.

\section{Способ повышения электрической перестройки спектра ФМР в композитных мультиферроидных структурах}

Обсудим теперь рост эффективности перестройки спектра ФМР при деформациях, создаваемых пьезоэлектрическим актюатором в пленках, подвергнутых статическому изгибу, например, за счет винтовой подачи. В этом случае высота прогиба пленки $\mathrm{h}$ определяется как

$$
h=h_{0}+\delta h,
$$

где $h_{0}$ и $\delta h$ - высоты прогиба, созданные винтом и пьезоактюатором при подаче на него напряжения $U$. При этом из $(2)-(5),(7)$ следует, что величина сдвига частоты ФМР

$$
\Delta \Omega\left(U, h_{0}\right) \sim\left(h_{0}^{2}+2 h_{0} \delta h_{E}+\delta h_{E}^{2}\right) .
$$

Можно видеть, что для некоторых двух фиксированных значений микровинтовой подачи $h_{01,2} \neq 0$ отношение $R$ сдвигов частоты ФМР $\Delta \Omega_{1,2}\left(U, h_{1,2}\right)$, вызванных удлинением актюатора на $\delta h$ под действием напряжения $U$, составит

$$
R=\frac{\Delta \Omega\left(U, h_{2}\right)}{\Delta \Omega\left(U, h_{1}\right)}=\frac{2 h_{02} \delta h_{E}+\delta h_{E}^{2}}{2 h_{01} \delta h_{E}+\delta h_{E}^{2}} .
$$

Из (9) следует, что в пленке, подвергнутой изгибной деформации за счет микровинтовой подачи на величину $h_{02} \neq 0$, чувствительность спектра ФМР к деформации пьезоактюатора вырастет в $R \approx\left(2 h_{02} / \delta h+1\right)$ раз относительно случая $h_{01}=0$.

На рис. 4 представлены зависимости $S_{21}(f)$ для структуры ЖИГ/Si при величине подаваемого на актюатор напряжения 0 (кривые 1) и $150 \mathrm{~V}$ (кривые 2). На рис. 4, $a$ представлены случаи ненагруженной пленки ЖИГ (кривая 1), и когда деформация пленки обеспечивалась только актюатором $\left(h_{0}=0, \delta h \approx 5 \mu \mathrm{m}\right.$, кривая 2$)$. Видно, что изменение частоты $f_{r}$ при увеличении $U$ от 0 до $150 \mathrm{~V}$ составляет $10 \mathrm{MHz}$. Однако если образец предварительно уже деформирован с помощью винтовой подачи $\left(h_{0} \approx 20 \mu \mathrm{m}, \delta h=0\right.$, кривая 1 на рис. $\left.4, b\right)$, аналогичное изменение частоты при $h_{0} \approx 20 \mu \mathrm{m}, \delta h=5 \mu \mathrm{m}$ составляет $25 \mathrm{MHz}$ (кривая 2 на рис. 4, $b$ ). Таким образом, показана возможность увеличения чувствительности перестройки частоты $f_{r}$ с помощью предварительной деформации пленки.

Отметим, что предложенный механизм „усиления“ влияния слабых деформаций на частоту ФМР может объяснять сильную немонотонность зависимости $f_{r}(P)$ в пленках ЖИГ/GaAs при малых нагрузках $P$ на пленку (кривая 2 на рис. 3). Для этого необходимо предположить, что неоднородности интерфейса и адгезии пленки к подложке приводят к встроенным статическим деформациям, аналогичным растяжению пленки при изгибе. Тогда, согласно (9), под влиянием слабой нагрузки изгиб пленки может быть существенно усилен. При этом увеличение деформации пленки может изменять характер адгезии пленки, что может приводить к релаксации встроенных напряжений и к немонотонности зависимости $f_{r}(P)$.

\section{Заключение}

Исследовано влияние деформаций растяжения на частоту ФМР $f_{r}$ субмикронных поликристаллических пленок ЖИГ/Si и ЖИГ/GaAs, полученных ионно-лучевым 
распылением. Показано, что зависимость $f_{r}$ от величины растяжения в пленках ЖИГ/Si имеет типичный для эпитаксиальных пленок ЖИГ характер, тогда как в пленках ЖИГ/GaAs наблюдается немонотонное изменение частоты ФМР при увеличении деформации. Такой характер зависимости $f_{r}(P)$ в пленках ЖИГ/GaAs связывается с наличием встроенных статических деформаций пленки, вызванных неоднородностью интерфейса и адгезии пленки к подложке. По величине частотного сдвига $\Delta \Omega$ максимума поглощения в спектре ФМР были рассчитаны магнитоупругие постоянные пленок ЖИГ/Si $\left(B \approx 0.8 \cdot 10^{6} \mathrm{erg} / \mathrm{cm}^{3}\right)$ и ЖИГ/GaAs $\left(B \approx 0.6 \cdot 10^{6} \mathrm{erg} / \mathrm{cm}^{3}\right)$, которые составили не более $\sim 16 \%$ от значений объемного поликристаллического ЖИГ. Предложен подход к увеличению эффективности электрической перестройки частоты в композитных мультиферроидных структурах за счет комбинации статических и динамических (вызванных пьезоэффектом) деформаций растяжения.

\section{Финансирование работы}

Работа выполнена при поддержке грантов Российского фонда фундаментальных исследований 16-29-14058 и 18-57-00008 и в рамках Государственного задания № 0030-2019-0013 „Спинтроника“.

\section{Конфликт интересов}

Авторы заявляют, что у них нет конфликта интересов.

\section{Список литературы}

[1] Бухараев А.А., Звездин А.К., Пятаков А.П., Фетисов Ю.К. // УФН. 2018. Т. 188. С. 1288-1330.

DOI: $10.3367 / \mathrm{UFNr} .2018 .01 .038279$

[2] Гуревич А.Г., Мелков Г.А. Магнитные колебания и волны. М.: Физматлит, 1994. 464 с.

[3] Balinskiy M., Chavez A.C., Barra A., Chiang H., Carman G.P., Khitun A. // Scientif. Reports. Vol. 8. P. 10867. DOI: 10.1038/s41598-018-28878-w

[4] Shone M. // Circuits, Systems and Signal Processing. 1985. Vol. 4. N 1-2. P.89-103.

[5] Stognij A.I., Tokarev V.V., Mitin Yu.N. // Mat. Res. Soc. Symp. Proc. 1992. Vol. 236. P. 331-334.

[6] Хивинщев Ю.В., Сахаров В.К., Высоцкий С.Л., Филимонов Ю.А., Стогний А.И., Никитов С.А. // ЖТФ. 2018. Т. 88. Вып. 7. C. 1060-1064. DOI: 10.21883/JTF.2018.07.46178.2448

[7] Stognij A.I., Lutsev L.V., Bursian V.E., Novitskii N.N. // J. Appl. Phys. 2015. Vol. 118. P. 023905. https://doi.org/10.1063/1.4926475

[8] Stognij A., Lutsev L., Novitskii N., Bespalov A., Golikova O., Ketsko V., Gieniusz R., Maziewski A. // J. Phys. D: Appl. Phys. 2015. Vol. 48. N 48. P. 485002-8. DOI: $10.1088 / 0022-3727 / 48 / 48 / 485002$

[9] Lutsev L.V., Stognij A.I., Novitskii N.N., Bursian V.E., Maziewski A., Gieniusz R. // J. Phys. D: Appl. Phys. 2018. Vol. 51. P. 355002. https://doi.org/10.1088/1361-6463/aad41b
[10] Bushnell S.E., Nowak W.B., Oliver S.A., Vittoria C. // Rev. Sci. Instrum. 1992. Vol. 63. N 3. P. 2021. https://doi.org/10.1063/1.1143159

[11] Smith A.R., Jones R.V. // J. Appl. Phys. 1963. Vol. 34. N 4. N 2. P. $1283-1284$.

[12] Щеглов В.И. // Микроэлектроника. 1987. Т. 16. Вып. 4. C. 374-376.

[13] Hoekstra B., van Doveren F., Robertson J.M. // Appl. Phys. 1977. Vol. 12. P. 261-263.

[14] Высочкий С.Л., Хивинцев Ю.В., Кожсевников А.В., Сахаров В.К., Филимонов Ю.А., Стогний А.И., Новиџкий Н.Н., Никитов С.А. // РЭ. 2019. Т. 64. № 12. С.1202-1211. DOI: $10.1134 / \mathrm{S} 0033849419100140$

[15] Piezomechanik GmbH, Munich 2006 Low Voltage Co-Fired Multilayer Stacks, Rings and Chips for Actuation Model Pst $150 / 2 \times 3 / 5$, low temperature.

[16] Тимошенко С.П., Гудьер Джк.Н. Теория упругости. М.: Наука, 1979. $560 \mathrm{c}$.

[17] Boyd E.J., Uttamchandani D. // J. Microelectromech. Syst. 2012. Vol. 21. N 1. P. 243-249 . DOI: $10.1109 /$ JMEMS.2011.2174415

[18] Gibbons D.F., Chirba V.G. // Phys. Rev. 1958. Vol. 110. P. 770.

[19] Chou H.M., Case E.D. // J. Mater. Sci. Lett. 1988. Vol. 7. N 11. P. 1217. DOI: $10.1007 / \mathrm{BF} 0072234$ 